\title{
Consumo e digestibilidade aparente de silagens de Brachiaria brizantha cv marandu adicionada de aditivos
}

\author{
[Intake and digestibility of silages of Brachiaria brizantha cv marandu with additives] \\ C.G. Jayme ${ }^{1}$, L.C. Gonçalves ${ }^{2}$, L.R. Molina ${ }^{3}$, D.G. Jayme ${ }^{2}$, D.A.A. Pires ${ }^{4}$, I. Borges ${ }^{2}$, G.H.F. Castro ${ }^{5}$ \\ ${ }^{1}$ Instituto Federal de Educação, Ciência e Tecnologia Sudeste de Minas Gerais Campus Rio Pomba - \\ ${ }^{2}$ Departamento de Zootecnia da EV-UFMG - Belo Horizonte, MG \\ ${ }^{3}$ Departamento de Clínica e Cirurgia Veterinária - EV-UFMG - Belo Horizonte, MG \\ ${ }^{4}$ Departamento de Zootecnia - UNIMONTES - Montes Claros, MG \\ ${ }^{5}$ Departamento de Zootecnia UFVJM - Diamantina, MG
}

\begin{abstract}
RESUMO
Avaliaram-se o consumo e a digestibilidade aparente da matéria seca, da proteína bruta e da energia e o balanço de nitrogênio de silagens de Brachiaria brizantha cv marandu sem aditivos (T1), $B$. brizantha cv marandu + inoculante bacteriano Sil-ALL C4 (T2), B. brizantha cv marandu + inoculante bacteriano Bactosilo C Tropical (T3) e B. brizantha cv marandu $+30 \%$ de cana-de-açúcar (T4) em ovinos. Não foram observadas diferenças no consumo de matéria seca (MS), proteína bruta (PB), energia bruta (EB), energia digestível (ED) e energia metabolizável (EM) entre os tratamentos ( $\mathrm{P}>0,05)$. Os maiores valores de digestibilidade aparente da MS, PB e EB foram para o T2, de 60,9\%, 44,3\% e 57,5\%, respectivamente, e os menores para o $\mathrm{T} 4,53,0 \%, 30,0 \%$ e $49,5 \%$, respectivamente $(\mathrm{P}<0,05)$. Todos os tratamentos apresentaram balanço de nitrogênio positivo e não diferiram entre si. A utilização de inoculantes bacterianos ou cana-de-açúcar não indicou aumento de consumo da matéria seca e energia das silagens. $\mathrm{O}$ inoculante SiL ALL C4 (T2) mostrou-se eficiente em aumentar o consumo e a digestibilidade da PB.
\end{abstract}

Palavras-chave: ovino, consumo voluntário, digestibilidade, inoculante bacteriano, silagem

\begin{abstract}
This experiment was carried out to estimate the voluntary intake, apparent digestibility and nitrogen balance of silages of Brachiaria brizantha $c v$ marandu without additives (T1), B. brizantha $c v$ marandu + inoculant Sil-ALL C4 (T2), B. brizantha cv marandu + inoculant Bactosilo C Tropical (T3) and B. brizantha $c v$ marandu $+30 \%$ of Sugar cane (T4) in sheep. No differences among silages regarding voluntary intake of: dry matter, crude protein, crude energy, digestible energy and metabolizable energy were found $(P>0.05)$. The highest apparent digestibility of dry matter, crude protein and crude energy were observed for $\mathrm{T} 2$, being $60.8 \%, 44.2 \%$ and $57.5 \%$, respectively, and the lowest for $\mathrm{T} 4$, with $53.0 \%$, $30.0 \%$ and $49.5 \%$, respectively $(P<0.05)$. All treatments showed positive nitrogen balance and did not differ among them. The use of an inoculant or sugar cane did not result in voluntary intake increase of dry matter, fibrous fractions and energy of silages. The inoculant Sil ALL C4 was efficient in increasing the intake and digestibility of $\mathrm{CP}$ and nitrogen balance.
\end{abstract}

Keywords: sheep, digestibility, voluntary intake, bacterium inoculant, silage

\section{INTRODUÇÃo}

Uma alternativa para os sistemas de produção de ruminantes é ensilar as pastagens excedentes ou, ainda, destinar campos exclusivos para produção de silagem, visto o seu custo reduzido por tonelada de matéria seca em relação às plantas tradicionais como milho e sorgo (Igarasi et al., 2002). O conhecimento da ingestão voluntária de alimentos por ruminantes tem grande

Recebido em 10 de junho de 2010

Aceito em 8 de abril de 2011

E-mail: cgjayme@gmail.com 
importância no estudo dos alimentos, pois pode restringir a utilização de alguns, especialmente aqueles ricos em frações fibrosas (Ørskov e Ryle, 1990). Mertens (1994) propõe que o consumo voluntário é regulado por três mecanismos: o fisiológico, em que a regulação é dada pelo balanço nutricional, o físico, relacionado à capacidade de distensão do rúmen e, ainda, o pisicogênico, que envolve o comportamento responsivo do animal a fatores inibidores ou estimuladores relacionados ao alimento ou ao ambiente. Os fatores físicos têm mais importância em dietas com baixas digestibilidades, e os fatores fisiológicos em dietas mais digestíveis (Conrad et al., 1964).

Este trabalho teve o objetivo de determinar o consumo voluntário e o coeficiente de digestibilidade aparente da matéria seca (MS), da proteína bruta (PB) e da energia, e o balanço de nitrogênio das silagens de Brachiaria brizantha cv marandu pura, adicionada de cana-de-açúcar ou aditivos bacterianos.

\section{MATERIAL E MÉTODOS}

Foi utilizada uma área de Brachiaria brizantha cv marandu já estabelecida em latossolo vermelho escuro. Com base na análise química do solo, no início do período chuvoso foi feita correção da acidez, aplicando-se $1500 \mathrm{~kg} / \mathrm{ha}$ de calcário dolomítico (PRNT: 63\%). Trinta dias depois, a pastagem passou por um corte de uniformização com roçadeira a $20 \mathrm{~cm}$ do nível do solo e recebeu adubação com $200 \mathrm{~kg}$ de ureia, $100 \mathrm{~kg}$ de cloreto de potássio e $300 \mathrm{~kg}$ de superfosfato simples.

A Brachiaria brizantha cv marandu foi submetida ao corte após 56 dias de crescimento a $20 \mathrm{~cm}$ do nível do solo utilizando-se roçadeira costal. A forrageira foi picada em picadeira estacionária em partículas de 10 a $30 \mathrm{~mm}$, e o material foi processado conforme os tratamentos: B. brizantha cv marandu sem aditivos (T1Preparo da solução: $5 \mathrm{~g}$ em $1 \mathrm{~L}$ de água limpa sem cloro ou qualquer outro poluente, em temperatura entre $20^{\circ} \mathrm{C}$ e $30^{\circ} \mathrm{C}$. Deixar em descanso após diluição por no mínimo quatro horas. Utilizar $1 \mathrm{~L}$ da solução/ $\mathrm{t}$ de forragem) $B$. brizantha cv marandu + inoculante bacteriano Sil-ALL C4 (T2 - Preparo da solução: 150g em $1 \mathrm{~L}$ de água limpa sem cloro ou qualquer outro poluente, em temperatura entre $20^{\circ} \mathrm{C}$ e $30^{\circ} \mathrm{C}$.
Deixar em descanso após diluição por, no mínimo, quatro horas. Utilizar $1 \mathrm{~L}$ da solução/ $\mathrm{t}$ de forragem), $B$. brizantha cv marandu + inoculante bacteriano Bactosilo C Tropical (T3) e B. brizantha cV marandu $+30 \%$ de cana-de-açúcar (T4). O inoculante Sil-ALL C4 é um produto à base de Streptococcus faecium, Pediococcus acidilactici, Lactobacillus plantarum, amilase, celulase e hemicelulase, com concentração de $8,0 \times 10^{10} \mathrm{UFC} / \mathrm{g}$ de forragem. O inoculante Bactosilo C Tropical é composto por enzimas - hemicelulase, celulase e amilase e cepas tropicalizadas de Lactobacillus plantaruam, Enterococcus faecium e Pediococcus spp, garantindo viabilidade celular de $10^{9} \mathrm{UFC} / \mathrm{g}$ do produto. Os inoculantes, depois de diluídos em água não clorada, de acordo com o preconizado pelo fabricante, foram distribuídos em frascos plásticos com tampa do tipo nebulizadora. O material foi ensilado em 20 tambores de 200 litros, revestidos internamente com saco plástico, totalizando cinco tambores por tratamento.

Depois de lacrados, os tambores foram transportados para o laboratório, onde foram mantidos em temperatura ambiente até a abertura, após 56 dias de fermentação. Foram coletadas amostras das silagens dos tambores que foram congeladas em câmara fria a $-17^{\circ} \mathrm{C}$. Posteriormente foram descongeladas, homogeneizadas, pesadas e pré-secas em estufa de ventilação forçada a $55^{\circ} \mathrm{C}$, por 72 horas, dentro de bandejas de alumínio. Após determinação da materia pré-seca, as amostras foram moídas em moinho estacionário ThomasWilley modelo 4, com peneira de $1 \mathrm{~mm}$, e guardadas em frascos plásticos vedados.

Para determinação do consumo voluntário e da digestibilidade aparente das silagens, foram utilizados 20 carneiros machos adultos, castrados, com raça e idade indefinidas, alojados em 20 gaiolas individuais, de metabolismo, e distribuídos de maneira uniforme quanto ao peso vivo e à localização na sala, com cinco repetições por tratamento. As gaiolas metabólicas individuais, confeccionadas em aço e piso com ripado de madeira, dispunham de bebedouro em aço inoxidável para água, de cocho para volumoso, e outro, de polietileno, para sal mineral. Água e mistura mineral foram fornecidas à vontade. 
O ensaio teve a duração de 26 dias, sendo 21 para adaptação e cinco para colheita de amostras, quando se realizaram colheitas de amostras do alimento oferecido, das sobras no cocho, das fezes e da urina, e dados de consumo das dietas e das produções fecal e urinária.

A quantidade de silagem fornecida foi registrada e realizada diariamente às sete horas e às 17 horas. Amostras das silagens fornecidas foram retiradas diariamente pela manhã, acondicionadas em sacos plásticos, identificadas e congeladas. $\mathrm{O}$ arraçoamento ocorreu de forma a se obterem $20 \%$ de sobras. Foram retiradas alíquotas da silagem fornecida, das sobras de silagem e das fezes, correspondentes a $20 \%$ do total diário, congelando-as para análises posteriores. Para a coleta de fezes, foi utilizado um fundo em funil nas gaiolas com uma caixa coletora. As fezes foram recolhidas duas vezes por dia, imediatamente após o fornecimento das dietas.

Para a colheita de urina, utilizaram-se funis de aço inoxidável acoplados ao fundo das gaiolas e baldes contendo $100 \mathrm{~mL}$ de ácido clorídrico $2 \mathrm{~N}$ como forma de se evitar a fermentação, a degradação e as perdas de nitrogênio. A coleta total de urina ocorreu uma vez ao dia, com mensuração do volume total obtido por animal e retirada de alíquotas de $10 \%$, que foram armazenadas em garrafas plásticas e congeladas.

As amostras diárias de fezes, alimento fornecido e sobras foram descongeladas, e o teor de matéria pré-seca foi determinado em estufa de ventilação forçada a $55^{\circ} \mathrm{C}$ por 72 horas. As amostras foram moídas em moinho estacionário tipo Thomas-Wiley, modelo 4, utilizando-se peneira de $1 \mathrm{~mm}$. Após a moagem das amostras diárias, procedeu-se à sua homogeneização para confecção das amostras compostas, que foram estocadas em temperatura ambiente em frascos de vidro com tampa.

As amostras compostas de fezes, silagens e sobras foram analisadas em duplicatas. Foram determinados os teores de matéria seca (MS) em estufa a $105^{\circ} \mathrm{C}$ (Oficial..., 1980), proteína bruta (PB) e conteúdo de nitrogênio $(\mathrm{N})$ pelo método de Kjedhal (Oficial..., 1995), e energia bruta
(EB) por combustão em bomba calorimétrica adiabática modelo PARR 2081 (Oficial..., 1995). $\mathrm{Na}$ urina determinaram-se os teores de energia bruta, nitrogênio e proteína bruta, seguindo-se as metodologias mencionadas. As digestibilidades da MS, PB e EB foram determinadas pelo método de coleta total de fezes descrito por Silva e Leão (1979).

O consumo voluntário de MS e de PB foi expresso em g/UTM/dia, o de EB, energia digestível e energia metabolizável em $\mathrm{kcal} / \mathrm{UTM} /$ dia, e todos foram determinados pela diferença entre o alimento consumido e as sobras. O consumo de MS digestível e PB digestível foi expresso em g/UTM/dia, o de energia digestível e o de energia metabolizável em kcal/UTM/dia, e todos foram determinados pela multiplicação entre consumo voluntário e digestibilidade de cada nutriente.

Os valores de energia digestível (ED) foram obtidos pela diferença entre a EB dos alimentos e das fezes. Os de energia metabolizável (EM) foram obtidos pela diferença entre energia digestível e perda de energia sob a forma de metano e urinária. Para cálculo das perdas de metano $(\mathrm{cm})$, foi utilizada a fórmula sugerida por Blaxter e Clapperton (1965) para animais sob o regime de mantença, em que: $\mathrm{cm}=3,67+$ 0,062D, e D representa a digestibilidade aparente da energia bruta do alimento.

O delineamento experimental utilizado foi o inteiramente ao acaso, com quatro tratamentos e cinco repetições. Os dados obtidos foram submetidos à análise de variância, utilizando-se o pacote estatístico do software SAS (1997).

\section{RESULTADOS E DISCUSSÃO}

A composição do material original ensilado encontra-se na Tab. 1 . Os teores de MS da forragem fresca variaram de 20,6\% a 22,4\%, verificados em T3 e T4, e de 18,9\% a 19,8\% na silagem, respectivamente. Todos os tratamentos apresentaram teores de PB próximos ou acima de 7\%, considerado o limite mínimo para o desenvolvimento adequado das bactérias ruminais (Van Soest, 1994). Os de energia bruta (EB) variaram de $3846,2 \mathrm{kcal} / \mathrm{kg}$ a $3927,4 \mathrm{kcal} / \mathrm{kg}$. 
Tabela 1. Teores de matéria seca (MS) da Brachiaria brizantha na forragem fresca e na silagem, proteína bruta (PB), energia bruta (EB), digestibilidade in vitro da matéria seca (DIVMS) e composição química e valores de $\mathrm{pH}$

\begin{tabular}{lcccc} 
& $\mathrm{T} 1$ & $\mathrm{~T} 2$ & $\mathrm{~T}$ & $\mathrm{~T} 4$ \\
\hline (\%) MS na forragem fresca & 21,35 & 21,69 & 20,61 & 22,44 \\
MS (\%) na silagem & 19,35 & 19,23 & 18,90 & 19,77 \\
$\mathrm{~PB}(\% \mathrm{MS})$ & 7,02 & 8,23 & 7,52 & 6,59 \\
EB (kcal/kg) & 3927,43 & 3918,42 & 3846,18 & 3882,63 \\
DIVMS (\%MS) & 58,59 & 60,14 & 61,01 & 58,83 \\
$\mathrm{pH}$ & 4,83 & 4,96 & 4,92 & 3,80 \\
$\mathrm{NH}_{3}$ /NT (\%MS) & 16,94 & 15,76 & 14,32 & 11,19 \\
\hline
\end{tabular}

T1: B. brizantha cv marandu sem aditivos; T2: B. brizantha cv marandu + inoculante bacteriano Sil-ALL C4; T3: $B$. brizantha cv marandu + inoculante bacteriano Bactosilo C Tropical; T3: e B. brizantha cv marandu $+30 \%$ de canade-açúcar.

Os teores de DIVMS foram próximos e variaram de 58,6\% a 61,0\%, observados em T1 e T3, respectivamente. A adição do inoculante bacteriano não causou alterações na MS e na DIVMS das silagens de Brachiaria brizantha. O menor valores de $\mathrm{pH}$ observado foi em T4, 3,8, e os demais tratamentos apresentaram valor de $\mathrm{pH}$ acima de 4,8. Os de $\mathrm{N}-\mathrm{NH}_{3} / \mathrm{NT}$ foram mais altos que $10 \%$ em todos os tratamentos avaliados.

Os valores de consumo voluntário da MS (CMS), digestibilidade aparente da matéria seca (DA MS) e consumo de matéria seca digestível (CMSD) estão apresentados na Tab. 2. Não foram observadas diferenças no consumo de MS entre os tratamentos $(\mathrm{P}>0,05)$, cuja variação foi de 44,07g/UTM/dia no T4 a 50,37g/UTM/dia no T2. O maior valor de DA MS ocorreu em T2, $60,9 \%$, semelhante ao do T1, 57,1\%, e ao do T3, $58,1 \%(\mathrm{P}>0,05)$, e maior que o do $\mathrm{T} 4,53,0 \%$ $(\mathrm{P}<0,05)$. Os valores de DAMS de T1 e T3 foram semelhantes entre si e entre os demais $(\mathrm{P}>0,05)$. O consumo de MS apresentou correlação positiva com a DAMS ( $r=0,52$;
$\mathrm{P}<0,01)$. O CMSD não apresentou diferença entre tratamentos $(\mathrm{P}>0,05)$, e seus valores variaram de 23,6g/UTM/dia a 30,7g/UTM/dia, observados em T4 e T2, respectivamente. De modo geral, avalia-se que o uso de aditivo bacteriano na ensilagem não proporciona efeito consistente sobre o consumo de MS. Esta afirmativa foi feita por Harrison et al. e Blauwikel (1994), que, em artigo de revisão, mostraram que os inoculantes bacterianos e suas associações com enzimas produzem efeitos variáveis sobre o consumo de MS. Os resultados deste experimento estão dentro dos valores observados por McDonald et al. (1991), que encontraram variação de CMS de silagens entre 20 e 75g/UTM/dia em ovinos. Considerando-se a necessidade de CMS de 51,02g/UTM/dia recomendada para a manutenção de ovinos pelo AFRC (Energy..., 1993), observa-se que as silagens avaliadas não atingiram essa exigência, o que pode ter limitado o desempenho dos animais que consumiram exclusivamente esse tipo de silagem.

Tabela 2. Consumo voluntário de matéria seca (CMS), digestibilidade aparente da matéria seca (DA MS) e consumo de matéria seca digestível (CMSD) das silagens de Brachiaria brizantha cv marandu

\begin{tabular}{lccccc}
\hline & $\mathrm{T} 1$ & $\mathrm{~T} 2$ & $\mathrm{~T} 3$ & $\mathrm{~T} 4$ & $\mathrm{CV}(\%)$ \\
\hline CMS, g/UTM/dia & 47,70 & 50,37 & 47,33 & 44,07 & 14,61 \\
DA MS, \% & $57,11 \mathrm{AB}$ & $60,88 \mathrm{~A}$ & $58,12 \mathrm{AB}$ & $52,98 \mathrm{~B}$ & 6,15 \\
CMSD, g/UTM/dia & 27,27 & 30,66 & 27,52 & 23,64 & 17,46 \\
\hline
\end{tabular}

Médias na linha seguidas de letras distintas diferem entre si pelo teste SNK $(\mathrm{P}<0,05)$. T1: $B$. brizantha cv marandu sem aditivos; T2: B. brizantha cv marandu + inoculante bacteriano Sil-ALL C4; T3: B. brizantha cv marandu + inoculante bacteriano Bactosilo C Tropical; T3: e B. brizantha cv marandu + 30\% de cana-de-açúcar.

Na Tab. 3, são apresentados os valores de consumo de EB (CEB), de (DAEB), consumo de ED (CED) e de EM (CEM). Não foram observadas diferenças entre os tratamentos quanto ao CEB (P>0,05), que variou de 168,00kcal/UTM/dia a 194,40kcal/UTM/dia, observados em T4 e T2, respectivamente. Observou-se correlação positiva entre CEB e 
CMS ( $r=0,99 ; \mathrm{P}<0,0001)$ e entre CEB e DAMS $(\mathrm{r}=0,53 ; \mathrm{P}<0,01)$, fato já assinalado por Crampton (1957) e Sanson e Clanton (1989), os quais consideram que o consumo de alimento está altamente correlacionado com a sua densidade calórica e o seu consumo de energia.

O maior valor de DAEB foi do T2, 57,5\%, e o menor o do $\mathrm{T} 4,49,5 \%$, diferentes entre si $(\mathrm{P}<0,05)$. Em T1 e T3 foram observados valores intermediários de $53,7 \%$ e $53,7 \%$, respectivamente, sendo semelhantes entre si e aos demais $(\mathrm{P}>0,05)$. Não foram observadas diferenças entre os tratamentos quanto ao consumo de energia digestível e de energia metabolizável $(\mathrm{P}>0,05)$, cuja variação foi de $128,50 \mathrm{kcal} / \mathrm{UTM} / \mathrm{dia}$, a 146,18kcal/UTM/dia, e de $108,64 \mathrm{kcal} / \mathrm{UTM} / \mathrm{dia}$ a $121,77 \mathrm{kcal} / \mathrm{UTM} / \mathrm{dia}$, valores observados em T4 e T2, respectivamente. Quanto ao consumo de energia digestível por grama de MS consumida/UTM (CED/CMS) e consumo de energia metabolizável por grama de MS consumida/UTM (CEM/CMS) também não foram observadas diferenças entre os tratamentos $(\mathrm{P}>0,05)$, fato atribuído à semelhança encontrada entre CMS, CED e CEM, uma vez que estas relações são dependentes destas variáveis. Os consumos oscilaram de 2,85Mcal ED/kgMS a 3,03Mcal ED/kgMS, e de 2,39Mcal EM/kgMS a 2,56Mcal EM/kgMS, observados em T4 e T3, respectivamente. O estudo dessas relações é importante na avaliação nutritiva dos alimentos, pois são parâmetros da eficiência de utilização da energia bruta. Entretanto, alta relação de eficiência somente é interessante se acompanhada por alto consumo de matéria seca. $O$ requisito médio de $E D$ para mantença de ovinos de 146,47kcal/UTM/dia (Nutrient..., 1984) praticamente foi suprido pelas silagens em T2 e T3, porém não o foi em T1 e T4, mas as diferenças entre os tratamentos não foram significativas $(\mathrm{P}>0,05)$.

Tabela 3. Consumo voluntário de energia bruta (CEB), digestibilidade aparente da energia bruta (DAEB), consumo de energia digestível (CED), consumo de energia metabolizável (CEM), consumo de energia digestível por grama de MS consumida/UTM (CED/CMS) e consumo de energia metabolizável por grama de MS consumida/UTM (CEM/CMS) de silagens de Brachiaria brizantha cv marandu

\begin{tabular}{lccccc}
\hline & $\mathrm{T} 1$ & $\mathrm{~T} 2$ & $\mathrm{~T}$ & $\mathrm{~T} 4$ & $\mathrm{CV}(\%)$ \\
\hline CEB, kcal/UTM/dia & 184,30 & 194,40 & 179,00 & 168,00 & 14,64 \\
DAEB, \% & $53,66 \mathrm{AB}$ & $57,54 \mathrm{~A}$ & $53,69 \mathrm{AB}$ & $49,45 \mathrm{~B}$ & 6,97 \\
$\mathrm{CED}$, & 140,14 & 146,18 & 143,59 & 128,50 & 21,29 \\
CEM, kcal/UTM/dia & 119,44 & 121,77 & 121,60 & 108,64 & 23,25 \\
CED/CMS, Mcal ED/kgMS & 2,93 & 2,89 & 3,03 & 2,85 & 8,41 \\
CEM/CMS, Mcal EM/kgMS & 2,49 & 2,40 & 2,56 & 2,39 & 10,40 \\
\hline
\end{tabular}

Médias na linha seguidas de letras distintas diferem entre si pelo teste SNK $(\mathrm{P}<0,05)$. T1: $B$. brizantha cv marandu sem aditivos; T2: B. brizantha cv marandu + inoculante bacteriano Sil-ALL C4; T3: B. brizantha cv marandu + inoculante bacteriano Bactosilo C Tropical; T3: e B. brizantha cv marandu + 30\% de cana-de-açúcar.

Os valores de consumo voluntário de proteína bruta (CPB), digestibilidade aparente da proteína bruta (DA PB) e consumo de proteína digestível (CPD) são apresentados na Tab. 4. O maior valor de CPB foi em T2, 4,47g/UTM/dia, diferente dos demais $(\mathrm{P}<0,05)$. Esse maior consumo provavelmente pode ser atribuído ao maior valor neste tratamento, apresentado na Tab.1. T1, T3 e T4 não diferiram entre si $(\mathrm{P}>0,05)$, com consumos de 3,53g/UTM/dia, 3,72 g/UTM/dia e 3,11g/UTM/dia, respectivamente.

O maior valor de DAPB, 68,8\%, ocorreu em T2, sendo diferente dos demais $(\mathrm{P}<0,05)$, que foram semelhantes entre si $(\mathrm{P}>0,05)$, com variação do consumo de 48,97g/UTM/dia a 54,82g/UTM/dia. $\mathrm{O}$ consumo de PB apresentou correlação positiva com o de MS ( $r=0,86 ; \mathrm{P}<0,0001)$. Isso se deve ao fato de, em dietas com maiores teores de PB, haver melhor desenvolvimento microbiano e, consequentemente, maior taxa de passagem e maior digestão da fração fibrosa (Van Soest, 1994). A DAPB apresentou correlação positiva com a DAMS $(\mathrm{r}=0,80 ; \mathrm{P}<0,0001)$. De acordo com Van Soest (1994), baixos teores de PB no alimento (inferiores a 6-8\%) limitam a fermentação ruminal reduzindo a digestibilidade da MS.

Os valores de CPD do T1, 1,87 g/UTM/dia, do T3, 2,04 g/UTM/dia, e do T4, 1,55g/UTM/dia, foram semelhantes entre si $(\mathrm{P}>0,05)$ e mais baixos que o do T2, 3,08g/UTM/dia $(\mathrm{P}<0,05)$. Mesmo não sendo observadas diferenças 
estatísticas entre os CMSD, no presente experimento, este parâmetro apresentou correlação positiva com CPD ( $\mathrm{r}=0,80$; $\mathrm{P}<0,0001$ ), sugerindo influência positiva dos mais altos teores de PB no consumo, como proposto por Van Soest (1994). Considerando-se o requisito médio de $\mathrm{PD}$ para mantença de ovinos, 2,58g/UTM/dia, segundo o NRC (Nutrient..., 1984), observa-se que apenas a silagem do $\mathrm{T} 2$ foi eficiente em suprir esses requisitos.

Este estudo apresentou valor mais baixo de CPB e CPD que os verificados por Almeida et al. (1995), os quais encontraram valores de
5,1g/UTM/dia e 2,7g/UTM/dia para silagem de milho e de 4,8g/UTM/dia e 2,8g/UTM/dia para silagem de sorgo, respectivamente, e mais baixos que os encontrados por Guimarães Júnior (2006), ao avaliar quatro genótipos de milheto, cujos valores médios de CPB e CPD foram de 4,91g/UTM/dia e 2,86g/UTM/dia. Reis et al. (2000) obtiveram consumos de PB e PB digestível de 3,88g/UTM/dia e 2,91g/UTM/dia, respectivamente, quando avaliaram silagens de capim-elefante, e Souza et al. (2003) observaram DAPB variando de $37,5 \%$ a $53,4 \%$, ao avaliarem o valor nutritivo de silagens de cinco híbridos de sorgo.

Tabela 4. Consumo voluntário de proteína bruta (CPB), digestibilidade aparente da proteína bruta (DAPB) e consumo de proteína digestível (CPD) de silagens de Brachiaria brizantha cv marandu

\begin{tabular}{lccccc}
\hline & $\mathrm{T} 1$ & $\mathrm{~T} 2$ & $\mathrm{~T} 3$ & $\mathrm{~T} 4$ & $\mathrm{CV}(\%)$ \\
\hline CPB, g/UTM/dia & $3,53 \mathrm{~B}$ & $4,47 \mathrm{~A}$ & $3,72 \mathrm{~B}$ & $3,11 \mathrm{~B}$ & 13,90 \\
$\mathrm{DAPB}, \%$ & $53,07 \mathrm{~B}$ & $68,76 \mathrm{~A}$ & $54,82 \mathrm{~B}$ & $48,97 \mathrm{~B}$ & 10,96 \\
$\mathrm{CPD}, \mathrm{g} / \mathrm{UTM} /$ dia & $1,87 \mathrm{~B}$ & 3,08A & $2,04 \mathrm{~B}$ & $1,55 \mathrm{~B}$ & 19,03 \\
\hline
\end{tabular}

Médias na linha seguidas de letras distintas diferem entre si pelo teste SNK $(\mathrm{P}<0,05)$. T1: $B$. brizantha cv marandu sem aditivos; T2: B. brizantha cv marandu + inoculante bacteriano Sil-ALL C4; T3: B. brizantha cv marandu + inoculante bacteriano Bactosilo C Tropical; T3: e B. brizantha cv marandu + 30\% de cana-de-açúcar.

O balanço de nitrogênio dos diferentes tratamentos pode ser visto na Tab. 5. O menor valor de $\mathrm{N}$ ingerido foi da silagem do $\mathrm{T} 4$, $7,44 \mathrm{~g} / \mathrm{dia}$, semelhante apenas ao $\mathrm{T} 1,9,16 \mathrm{~g} / \mathrm{dia}$ $(\mathrm{P}>0,05)$, e diferente dos demais $(\mathrm{P}<0,05)$. T2 com 12,17g/dia e T3 com 11,14g/dia foram semelhantes entre si e ao T1 $(\mathrm{P}>0,05)$. Essas diferenças são atribuídas aos diferentes teores de $\mathrm{PB}$ das silagens utilizadas, pois o $\mathrm{N}$ ingerido apresentou correlação positiva com o CPB $(\mathrm{r}=0,74 ; \mathrm{P}<0,002)$.

Os teores de $\mathrm{N}$ fecal e $\mathrm{N}$ urinário não apresentaram diferença entre os tratamentos e variaram de 3,75g/dia a 5,09g/dia, e de $0,157 \mathrm{~g} / \mathrm{dia}$ a $0,220 \mathrm{~g} / \mathrm{dia}$, respectivamente $(\mathrm{P}>0,05)$. $\mathrm{O}$ teor de $\mathrm{N}$ fecal apresentou correlação negativa com a DAPB ( $\mathrm{r}=-0,45$; $\mathrm{P}<0,04)$.

$\mathrm{O}$ maior valor de $\mathrm{N}$ retido foi para o $\mathrm{T} 2$, $8,15 \mathrm{~g} /$ dia, sendo diferente dos demais $(\mathrm{P}<0,05)$. Este fato pode ser explicado pela maior DAPB dessa silagem, pois o $\mathrm{N}$ retido apresentou correlação positiva com a DAPB ( $\mathrm{r}=0,85$; $\mathrm{P}<0,0001)$, e maior digestibilidade aparente da energia bruta observada, já que o $\mathrm{N}$ retido apresentou correlação positiva com DAEB
( $\mathrm{r}=0,74 ; \mathrm{P}<0,0002$ ), aumentando, com isso, a eficiência no aproveitamento da proteína (Silva e Leão, 1979). O menor valor de $\mathrm{N}$ retido foi do $\mathrm{T} 4,3,53 \mathrm{~g} /$ dia, que foi semelhante ao $\mathrm{T} 1$ $(\mathrm{P}>0,05)$ e diferente dos demais $(\mathrm{P}<0,05)$.

Os valores de $\mathrm{N}$ retido/ $\mathrm{N}$ ingerido de $\mathrm{T} 1$, $\mathrm{T} 3$ e $\mathrm{T} 4$ foram semelhantes entre si $(\mathrm{P}>0,05)$ e menores que do T2 $(\mathrm{P}<0,05)$. Estes resultados refletem a importância não apenas do teor de $\mathrm{PB}$ do alimento mas também de sua digestibilidade e da relação proteína-energia, já que os resultados de $\mathrm{N}$ retido/N ingerido apresentaram correlação positiva com a DA PB ( $\mathrm{r}=0,99$; $\mathrm{P}<0,001)$ e com a DAEB $(\mathrm{r}=0,77 ; \mathrm{P}<0,0001)$, demonstrando tendência semelhante à observada para a digestibilidade da proteína bruta.

A relação energia proteína da dieta está intimamente relacionada ao crescimento microbiano e ao consumo de alimento (Hennessy, 1980). Segundo Andrigueto et al. (1990), o balanço de nitrogênio pode ser indicativo do metabolismo proteico animal, sendo mais eficiente que a digestibilidade e o consumo de proteína para evidenciar se há perda ou não de proteínas pelo organismo. Martins et al. (2003) encontraram valores de $\mathrm{N}$ ingerido e $\mathrm{N}$ 
retido de 10,84g/dia e 4,80g/dia, respectivamente, e relação $\mathrm{N}$ retido/ $\mathrm{N}$ ingerido de 44,3\%, ao avaliarem silagem de sorgo. Já Freitas et al. (2003) verificaram relação N retido/ $\mathrm{N}$ ingerido de $51,2 \%$ e teores de $\mathrm{N}$ ingerido e $\mathrm{N}$ retido de 11,15 g/dia e 5,69 g/dia em silagem de milho, respectivamente.

Tabela 5. Balanço de nitrogênio de silagens de Brachiaria brizantha cv marandu

\begin{tabular}{lccccc} 
& $\mathrm{T} 1$ & $\mathrm{~T} 2$ & $\mathrm{~T}$ & $\mathrm{~T} 4$ & $\mathrm{CV}(\%)$ \\
\hline N ingerido, g/dia & $9,16 \mathrm{AB}$ & $12,17 \mathrm{~A}$ & $11,14 \mathrm{~A}$ & $7,44 \mathrm{~B}$ & 13,85 \\
$\mathrm{~N}$ fecal, g/dia & 4,31 & 3,79 & 5,09 & 3,75 & 21.64 \\
$\mathrm{~N}$ urinário, g/dia & 0,186 & 0,220 & 0,192 & 0,157 & 26.97 \\
N retido, g/dia & $4,66 \mathrm{BC}$ & $8,15 \mathrm{~A}$ & $5,85 \mathrm{~B}$ & $3,53 \mathrm{C}$ & 16,59 \\
\% N retido/N ingerido & $50,97 \mathrm{~B}$ & $66,95 \mathrm{~A}$ & $53,12 \mathrm{~B}$ & $46,86 \mathrm{~B}$ & 11,42 \\
\hline
\end{tabular}

Médias na linha seguidas de letras distintas diferem entre si pelo teste SNK $(\mathrm{P}<0,05)$. T1: $B$. brizantha cv marandu sem aditivos; T2: B. brizantha cv marandu + inoculante bacteriano Sil-ALL C4; T3: B. brizantha cv marandu + inoculante bacteriano Bactosilo C Tropical; T3: e B. brizantha cv marandu + 30\% de cana-de-açúcar.

\section{CONCLUSÕES}

A utilização de inoculantes bacterianos ou canade-açúcar, não resulta em aumento de consumo e digestibilidade da matéria seca e energia das silagens para ovinos. $\mathrm{O}$ consumo, a digestibilidade da proteína bruta e o balanço de nitrogênio foram aumentados com a utilização do inoculante bacteriano SiL ALL C4.

\section{AGRADECIMENTOS}

À Fundação de Amparo à Pesquisa do Estado de Minas Gerais - FAPEMIG e ao Conselho Nacional de Desenvolvimento Científico e Tecnológico - CNPq, pelo apoio concedido.

\section{REFERÊNCIAS BIBLIOGRÁFICAS}

ALMEIDA, M.F.; VON TIESENHAUSEN, I.M.E.V.; AQUINO, L.H. et al. Composição química e consumo voluntário das silagens de sorgo, em dois estádios de corte, girassol e milho para ruminantes. Cienc. Prat., v.19, p.315-321, 1995.

ANDRIGUETO, J.M.; PERLY, L.; MINARDI, I. et al. Nutrição animal: bases e fundamentos da nutrição animal. Rio de Janeiro: Nobel, 1990. v.1, 389p.

BLAXTER, K.L.; CLAPPERTON, J.L. Prediction of the amount of methane produced by ruminants. Br. J. Nutr., v.19, p.511-522, 1965.

CONRAD, H.R.; PRATT, A.D.; HIBSS, J.D.W. Regulation of feed intake in dairy cows. I. Change in importance of physiological factors with increasing in digestibility. J. Dairy Sci., v.48, p.47-54, 1964.

CRAMPTON, E.W. Interrelations between digestible nutrient and energy content, voluntary dry matter intake, and the overall. J. Anim. Sci., v.16, p.546-552, 1957.
ENERGY and protein requirements of ruminants. Wallingford: CAB International, 1993. 159p.

FREITAS, G.A.R.; COELHO, S.G.; GONÇALVES, L.C. et al. Consumo e digestibilidade aparente da matéria seca, proteína e energia bruta, e balanço de nitrogênio das silagens de cinco genótipos de milho. Arq. Bras. Med. Vet. Zootec., v.55, p.443-449, 2003.

GUIMARÃES JÚNIOR, R. Avaliação nutricional de silagens de milheto [Pennisetum glaucum (L). R. Br.]. 2006. 78f. Tese (Doutorado) - Escola de Veterinária, Universidade Federal de Minas Gerais, Belo Horizonte, MG.

HARRISON, J. H.; BLAUWIEKEL, R. Fermentation and utilization of grass silage. J. Dairy Sci., v.77, p.3209- 3235, 1994.

HENNESSY, D. W. Protein nutrition of ruminants in tropical areas of Australia. Trop. Grassl., v.14, p.260265, 1980.

IGARASI, M.S.; NUSSIO, L.G.; BRUNO, E.J.M. Levantamento de índices técnicos associados à produção de silagens de gramíneas tropicais. In: REUNIÃO ANUAL DA SOCIEDADE BRASILEIRA DE ZOOTECNIA, 39., 2002. Recife. Anais... Recife: SBZ, 2002. CD-ROM

MARTINS, R.G.R.; GONÇALVES, L.C.; RODRIGUES, J.A.S. et al. Consumo e digestibilidade aparente da matéria seca, da proteína bruta e da energia de silagens de quatro genótipos de sorgo (Sorghum bicolor (L.) Moench) por ovinos. Arq. Bras. Med. Vet. Zootec., v.55, p.341-345, 2003.

MERTENS, D.R. Predicting intake and digestibility using mathematical models of ruminal function. $J$. Anim. Sci., v.64, 1548-1552, 1994.

McDONALD, P.; HENDERSON, A.R.; HERON, S.J.E. The biochemistry of the silage. Edinburg: J. Wiley and Sons, 1991. 226p. 
NUTRIENT requirements of domestic animals: nutrient requirements of sheep. 16.ed. Washington: National Academic of Science, 1984. 90p.

OFFICIAL methods of analysis. 13. ed.IWashington, DC: AOAC, 1980. 1015p.

OFFICIAL methods of analysis. 16.ed. IWashington, DC: AOAC, 1995. 2000p.

ØRSKOV, E.R.; RYLE, M. Energy nutrition in ruminants. London: Elsevier, 1990. 149p.

REIS, J.; PAIVA, P.C.A.; VON TIESENHAUSEN, I.M.E.V.; et al. Composição química, consumo voluntário e digestibilidade de silagens de resíduos do fruto de maracujá (Passiflora edulis Sims f. flavicarpa) e de capim-elefante (Pennisetum purpureum Schum) cv. Cameroon e suas combinações. Cienc. Agrotec., v.24, p.213-224, 2000.
SANSON, D.W.; CLANTON, D.C. Intake and digestibility of low quality meadow hay by cattle receiving various levels of whole shelled corn. $J$. Anim. Sci., v.67, p.2854-2862, 1989.

SILVA, J.F.C.; LEÃO, M.I. Fundamentos de nutrição de ruminantes. Piracicaba: Livroceres, 1979. 380p.

SOUZA, V.G.; PEREIRA, O.G.; MORAES, S.A. et al. Valor nutritivo de silagens de sorgo. Rev. Bras. Zootec., v.32, p.753-759, 2003.

VAN SOEST, P.J. Nutritional ecology of the ruminant. 2.ed. Ithaca: Cornell University, 1994. 476p. 